\title{
A prescrição de tecnologias assistivas a partir dos princípios da tecnologia social: a visão dos estudantes de Terapia Ocupacional
}

\author{
Letícia Reichert ${ }^{\mathrm{a}}$, Taísa Gomes Ferreira ${ }^{\mathrm{b}}$ \\ aPrefeitura Municipal de Caçador, Caçador, SC, Brasil.

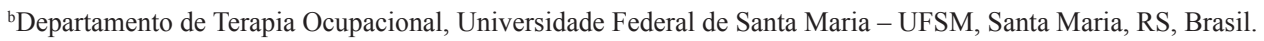

\begin{abstract}
Resumo: Introdução: A Tecnologia Social (TS) é vista como um conjunto de intervenções sociais de caráter multidisciplinar, que busca melhorias nas condições de vida da população e soluções participativas, simples e de baixo custo para problemas encontrados nas diferentes camadas da sociedade. A terapia ocupacional é uma profissão que visa à inclusão socioeconômica, à saúde e ao bem-estar, podendo utilizar-se das Tecnologias Assistivas (TA) para facilitar o desempenho de pessoas com deficiência na realização das atividades. Tanto a terapia ocupacional quanto as TA podem se inserir em projetos de TS, pois buscam a melhoria na qualidade de vida das pessoas, considerando a sua subjetividade e o contexto em que vivem. Objetivo: Comparar e debater os diferentes discursos de alunos referentes aos conceitos de TS e TA, e à construção de TA, a partir dos princípios da TS. Método: Realizou-se uma pesquisa qualitativa, com entrevista semiestruturada, utilizando-se o Discurso do Sujeito Coletivo como metodologia para análise das informações coletadas. Resultados: As informações das entrevistas geraram seis ideias: tecnologia social de baixo custo; ações desenvolvidas em conjunto e construídas com base em uma demanda; recursos, adaptações, equipamentos de auxílio para as pessoas/produto pronto; tecnologia que busca auxiliar as pessoas levando em conta o contexto; prescrições utilizando materiais de baixo custo encontrados na comunidade, e projetos construídos com o sujeito de forma interdisciplinar. Conclusão: Observa-se que, de forma geral, não foram discutidas questões importantes que envolvem o conceito de TS e TA, indicando a necessidade de pensar em estratégias de ensino que incentivem a discussão destas questões.
\end{abstract}

Palavras-chave: Terapia Ocupacional, Tecnologia de Baixo Custo, Equipamentos de Autoajuda, Ensino Superior.

\section{Assistive technology prescription from the principles of social technology: the Occupational Therapy students view}

\begin{abstract}
Introduction: Social Technology (ST) is seen as a set of multidisciplinary social interventions seeking improvements in the population living conditions and participative, simple and inexpensive solutions to problems encountered in different layers of society. Occupational therapy is a profession that aims to socio-economic inclusion, health and well-being, using the Assistive Technology (AT) to allow people with disabilities to perform activities. Therefore, both occupational therapy and AT can be inserted in ST projects, as they seek to improve the quality of life of people with disabilities, considering their subjectivity and the context in which they live. Objective: to compare and discuss the different students speeches regarding the concepts of ST and AT and the construction of AT from the principles of ST. Method: we conducted a qualitative research with semi-structured interview, using the Discourse of the Collective Subject as a methodological technique for organizing data. Results: interview data generated six central ideas, low-cost social technology; joint actions developed and made based on a demand; resources, adaptations, assistance equipment to ready people/product; technology that seeks to help people
\end{abstract}

Autor para correspondência: Letícia Reichert, Rua Herculano Coelho de Souza, 1157, Reunidas, CEP 89500-000, Caçador, SC, Brasil, e-mail: lereichert.sjo@gmail.com

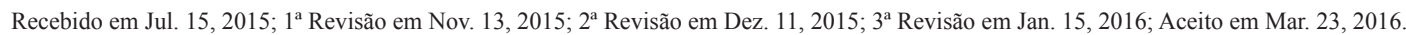


considering the context; prescription using low-cost equipment found in the community and projects made with the character in an interdisciplinary way. Conclusion: we observed that, in general, important issues have not been discussed involving the ST and AT concept, indicating the need to think about teaching strategies that encourage discussion of these issues.

Keywords: Occupational Therapy, Low-cost Technology, Self-care Equipment, Higher Education.

\section{Introdução}

A prescrição de tecnologias assistivas (TA), a partir dos princípios da tecnologia social (TS), pode proporcionar a construção de soluçôes de modo coletivo e autônomo pelos envolvidos, impactando na usabilidade.

A TS é vista como um conjunto de intervençôes sociais que buscam melhorar as condiçôes de vida da população e oferecer soluçóes participativas, simples e de baixo custo para problemas encontrados nas diferentes camadas da sociedade, implicando empoderamento, participação das pessoas e autogestão. Pode ser compreendida como um

[...] conjunto de técnicas e metodologias transformadoras, desenvolvidas e/ou aplicadas na interação com a população e apropriadas por ela, que representam soluçôes para inclusão social e melhoria das condiçóes de vida (INSTITUTO..., 2004, p. 26).

A adoção do termo 'TS' ocorreu a partir da necessidade de nomear as intervençóes sociais que se destacam pela melhoria na qualidade de vida da população, buscando soluçôes que se relacionam muito com a realidade local em que são aplicadas. A TS visa à sustentabilidade econômica, social e ambiental por meio da participação e apropriaçáo dos participantes e de outras pessoas envolvidas, produzindo novos conhecimentos e aprendizagens (BRASIL, 2012).

Assim, como a Terapia Ocupacional é um campo de conhecimento que busca, por meio do uso de atividades e de estratégias de intervenção e inclusão socioeconômica, promover emancipação e autonomia de pessoas que apresentam temporariamente ou definitivamente dificuldade na inserção e participação na vida social (WORLD..., 2001), pode inserir-se em projetos de TS. O papel da Terapia Ocupacional dentro de projetos de TS pode ser muito importante, pois ambos visam à melhoria na qualidade de vida das pessoas, levando em conta sua subjetividade e o seu contexto.

Terapeutas ocupacionais vêm trabalhando com a TS, utilizando atividades como um recurso mediador para buscar demandas, aproximação e fortalecimento dos sujeitos. Quando utiliza esse referencial, o terapeuta ocupacional reconhece as necessidades do sujeito e desenvolve suas capacidades para buscar soluções próprias e criativas (LOPES et al., 2011).

Desde o surgimento da profissão, o terapeuta ocupacional utiliza recursos tecnológicos que visam à participaçáo e facilitam o desempenho de pessoas com deficiência na realizaçáo de atividades nos diversos ambientes da sociedade. Esses recursos estão muito próximos do nosso dia a dia, impressionando por sua simplicidade ou por sua alta tecnologia (VARELA, 2010).

Tais recursos tecnológicos recebem diferentes nomes nos documentos relacionados às políticas das organizaçóes de pessoas com deficiência. O termo mais utilizado é TA, aprovado no Brasil, em agosto de 2007, pelo Comitê de Ajudas Técnicas (CAT), o qual define a TA como:

Uma área do conhecimento, de característica interdisciplinar, que engloba produtos, recursos, metodologias, estratégias, práticas e serviços que objetivam promover a funcionalidade, relacionada à atividade e participação, de pessoas com deficiência, incapacidades ou mobilidade reduzida, visando sua autonomia, independência, qualidade de vida e inclusão social (BRASIL, 2007, p. 3).

A TA contribui para proporcionar ampliação do desempenho na realização de atividades e busca promover maior independência e inserção social. São recursos pessoais, que atendem a necessidades diretas do usuário. Para haver uma maior adesão quanto ao uso da tecnologia e para suprir as necessidades do usuário, é necessário ouvir sua demanda, levar em conta o contexto em que vive e, também, valorizar seu conhecimento (GALVÃO FILHO, 2009). Portanto, o CAT entende que a TA é uma área do conhecimento que precisa ser interdisciplinar para poder alcançar seu principal objetivo: promover a funcionalidade de pessoas com deficiência e com mobilidade reduzida ou de idosos, visando a sua autonomia, independência e inclusão social.

O terapeuta ocupacional, em propostas de inclusão social, atua nas condiçốes de acessibilidade e utiliza 
tecnologias com o objetivo de gerar independência e funcionalidade (MARINS; EMMEL, 2011).

Muitos profissionais possuem aptidão para desenvolver ações no campo da TA, tais como educadores, terapeutas ocupacionais, fonoaudiólogos, fisioterapeutas, psicólogos, enfermeiros, assistentes sociais, oftalmologistas, engenheiros, especialistas em audição e protéticos (PELOSI, 2010; VARELA, 2010).

Segundo Marins e Emmel (2011), a intervenção do terapeuta ocupacional na TA busca desenvolver as funçôes físicas, sociais e psicológicas para favorecer o máximo desempenho da atividade ocupacional do sujeito. Seu conhecimento específico pode contribuir para melhorar a funcionalidade, o desempenho e a autonomia de uma pessoa que esteja com seu desempenho ocupacional comprometido.

$\mathrm{Na}$ TA, o terapeuta ocupacional, especificamente, tem competência para instruir o uso apropriado do recurso e orientar outras pessoas envolvidas sobre o uso dessa tecnologia. Esse profissional também pode avaliar a necessidade dos usuários, suas habilidades físicas, sensoriais e motoras; a receptividade do indivíduo quanto à modificação ou ao uso da adaptação; sua condição sociocultural e as características físicas do ambiente em que a tecnologia será utilizada (CANADIAN..., 2003 apud PELOSI, 2005). Para desenvolvimento desses recursos, é de extrema importância considerar os princípios de Desenho Universal e da TS (BRASIL, 2007).

Sabendo que muitas açóes de TS envolvem, logo de início, mobilização e conscientização, e que seu objetivo é despertar a democracia ativa e canalizar energias para buscar soluçôes e garantir direitos (INSTITUTO..., 2007), o conhecimento das pessoas sobre sua capacidade e como ela influencia em seu cotidiano auxilia na reaplicação da TS, pois, dessa forma, o indivíduo apropria-se do processo (INSTITUTO..., 2007).

Então, ao compreender a TS como técnicas e metodologias transformadoras que, por meio do conhecimento local, são desenvolvidas junto à população e vislumbram soluções para inclusão social e melhoria das condiçôes de vida, é possível perceber que as iniciativas de TS buscam construir um espaço de aprendizagem, em que homens, mulheres, pessoas com deficiência e seus familiares devem estar envolvidos em constante processo de ação e reflexão. Compreende-se, assim, que todos podem aprender com a interaçáo entre o pensamento científico e popular, gerando novos conhecimentos.

Assim, a partir dessa discussão, intui-se que este processo de construção coletiva e de apropriação do conhecimento da TS pode ampliar a adesão às TA. Tal ampliação na adesão se justifica pelo fato de que, por meio da apropriação do conhecimento, as pessoas compreendam a importância dessas tecnologias e as utilizem. Para Costa (2013):

Buscar soluções tecnológicas para problemas populares não pode significar soluçôes padronizadas e em massa. A construção e formulação tecnológica devem envolver movimentos sociais, os próprios beneficiários e os atores dos contextos específicos (COSTA, 2013, p. 22).

A TS apresenta-se como uma resposta mais próxima das demandas da sociedade, em que os atores principais são a própria comunidade, buscando um modelo de desenvolvimento social centralizado no processo de inclusão social (FERNANDES; MACIEL, 2010); e, para que haja uma maior aceitação das TS, de acordo com Silva e Alencar (2014), é imprescindível a socialização da informação.

Assim, incluir na formação do terapeuta ocupacional a discussão da TS e a possibilidade da prescrição de TA a partir desses princípios pode ampliar o instrumental desse profissional e a eficiência de suas açôes na área em questão.

Dentro do curso de Terapia Ocupacional da Universidade Federal de Santa Maria, os alunos têm contato com os conteúdos da área da Tecnologia Assistiva através das disciplinas obrigatórias "Órteses e Próteses" e "Tecnologia Assistiva”; porém, sabe-se que não acessam durante a graduação a discussão sobre TS e, segundo o CAT (BRASIL, 2007), para o desenvolvimento da TA, é importante considerar os princípios do Desenho Universal e da Tecnologia Social.

Diante disso, o Departamento de Terapia Ocupacional, juntamente com o Departamento do Curso de Desenho Industrial, desenvolveu o projeto "Capacitação de discentes para a produção de tecnologia social a pessoas com deficiência e mobilidade reduzida em comunidades de baixa renda no município de Santa Maria”, organizado a partir de duas Disciplinas Complementares de Graduação (DCGs) - "Tecnologias Sociais e pessoas com deficiência I" e "Tecnologias Sociais e pessoas com deficiências II - com os seguintes objetivos: conhecer o impacto da deficiência na vida cotidiana; conhecer e aplicar a metodologia e os processos de implementação de TS aplicada a construçáo de TA e adequação ambiental, e capacitar alunos dos cursos de Terapia Ocupacional e Desenho Industrial/Projeto de Produto a confeccionar dispositivos de TA e a realizar adequaçóes ambientais a partir da metodologia 
das TS. Foram utilizadas metodologias ativas como estratégia de ensino-aprendizagem.

Assim, através da comparação entre os discursos, buscou-se analisar se, para os alunos que frequentaram as DCGs, houve ampliaçáo de conceitos/conteúdos vigentes e se eles foram beneficiados com as discussōes sobre TA e TS realizadas nas aulas.

\section{Método}

Este estudo é parte de um projeto de pesquisa intitulado "A prescrição de Tecnologias Assistivas a partir dos princípios da Tecnologia Social: a visão dos estudantes de terapia ocupacional", que buscou analisar qualitativamente a influência das DCGs no discurso de alunos que as cursaram, comparando-os com o discurso de alunos que não tiveram a chance de cursá-las. Essas disciplinas foram ofertadas no primeiro e segundo semestre do ano de 2014 para dez alunos que estavam cursando o curso de Terapia Ocupacional, sendo seis alunos do sétimo semestre, dois alunos do sexto semestre e dois alunos do quinto semestre, e ainda para quatro alunos de semestres concomitantes ao curso de Desenho Industrial/Projeto de Produto da Universidade Federal de Santa Maria (UFSM). As disciplinas foram ministradas por docentes dos dois departamentos, a fim de capacitar os alunos a prescrever dispositivos de TA e adequaçóes ambientais a partir da metodologia da TS. Para isso, foram necessárias discussōes visando à ampliação da compreensão do impacto da deficiência na vida cotidiana e da aplicação da metodologia e de processos de implementação de TS aplicada à construçáo de TA.

A coleta das informaçôes para a realização deste estudo foi realizada no prédio $26 \mathrm{C}$ anexo do Centro de Ciências da Saúde da UFSM. Para garantir a veracidade dessas informaçôes, foi utilizado um gravador durante as entrevistas, que foram gravadas e arquivadas em oito arquivos individuais e transcritas na íntegra, com o consentimento dos alunos.

$\mathrm{O}$ instrumento de pesquisa utilizado para coletar as informaçôes consistiu em uma entrevista semiestruturada, com um roteiro elaborado pela pesquisadora, constituído de questóes simples, com perguntas que contribuíssem para responder o objetivo da pesquisa, objetivando reconhecer a influência do conceito de TS na construção de TA. As perguntas utilizadas na pesquisa foram: Você sabe o que é Tecnologia Social? Para você, qual seria a definição de TS? Você sabe o que é Tecnologia Assistiva? Para você, qual seria a definição de TA? Acredita que seja possível a construção de Tecnologias Assistivas aliadas às propostas da Tecnologia Social? Como você acredita que seriam esses projetos? Como seria a participação de terapeutas ocupacionais nesses projetos? Buscou-se, dessa forma, compreender qual a concepção que os sujeitos traziam sobre os conceitos de TS e TA, e também sobre a prescrição de projetos de TA por meio dos princípios da TS.

Vale ressaltar que foram realizadas duas entrevistas pré-teste com dois alunos (um que cursou as DCGs e outro que não as cursou) para verificar se o aluno captava os dados que se fazem necessários para responder aos objetivos da pesquisa.

Incluíram-se, neste estudo, alunos do quinto ao sétimo semestre, matriculados e aprovados nas DCGs. Os critérios de exclusão deste estudo foram alunos reprovados nas DCGs, alunos de semestres não concomitantes aos frequentados pelos alunos que cursaram a disciplina, alunos de outros cursos e alunos de outras instituiçóes. Os sujeitos da pesquisa totalizaram oito graduandos do curso de Terapia Ocupacional da UFSM, que estavam matriculados entre o quinto e o sétimo semestre. Foram selecionados quatro alunos entre os dez que cursaram as disciplinas: dois do sétimo semestre, um do sexto semestre e um do quinto semestre, e mais quatro alunos de semestres concomitantes que não cursaram a disciplina.

As entrevistas foram transcritas, organizadas e analisadas a partir da análise do Discurso do Sujeito Coletivo (DSC), que visa a construir o pensamento e revelar o modo como as pessoas pensam e manifestam posicionamentos sobre determinado assunto. Trata-se de um compartilhamento de ideias dentro de um grupo social, entendendo-se por discurso todo posicionamento argumentado (LEFÈVRE; LEFĖVRE, 2005).

O DSC consiste em analisar o material verbal coletado, extraindo-se de cada uma das entrevistas as ideias centrais (IC), ancoragens (AC) e as suas correspondentes expressóes-chave (ECH), que compóem um ou vários discursos-síntese, na primeira pessoa do singular. Dessa forma, o sujeito coletivo se expressa por meio de um discurso emitido no que se poderia chamar de primeira pessoa coletiva do singular, pois várias pessoas discursaram sobre determinado tema e a síntese dos discursos dos entrevistados representa o DSC (LEFÈVRE; LEFÈVRE, 2005). A análise das entrevistas e a construção dos DSCs compreenderam as seguintes etapas:

a) Identificação, a partir dos discursos obtidos através das entrevistas, das ideias centrais de cada resposta; 
b) Construção, com base nos dados obtidos anteriormente, do DSC;

c) Comparação entre os discursos dos discentes que participaram da DCG e os discursos dos que náo participaram.

Os discursos foram construídos a partir de fragmentos de discursos de sentido semelhante obtidos nas entrevistas. Vale ressaltar que o processo de construçấo dos discursos foi acompanhado por um professor de outro departamento da área da saúde com ampla experiência na metodologia proposta.

Este projeto foi aprovado pelo comitê de ética da UFSM sob CAEE n.o 38714614.1.0000.5346. O Termo de Consentimento Livre e Esclarecido foi apresentado aos alunos que aceitaram participar da pesquisa.

\section{Resultados e Discussão}

Durante as gravaçóes, foi possível perceber, quanto aos alunos que não frequentaram a DCG, uma dificuldade de formular o conceito sobre TS e também de pensar em projetos que a envolvessem. As respostas foram sucintas, tendo sido necessário repetir a pergunta sobre a TS para que se obtivesse uma resposta. Duas alunas solicitaram uma pausa na gravação a fim de obter mais tempo para formular a resposta. Também o entrevistador foi questionado algumas vezes com o intuito de avaliar se a resposta dada era correta, não tomando ele nenhum posicionamento para não interferir na resposta. Vale ressaltar que, dentre as oito entrevistadas, duas relataram nunca terem ouvido falar sobre a TS.

Já as entrevistas dos alunos que frequentaram a DCG ocorreram sem interrupçôes e as respostas apresentaram mais complexidade na tentativa de formular os conceitos.

Para melhor compreensão e possibilidade de comparação dos resultados, optou-se por agrupar os discursos em três temas distintos, apresentando primeiro o discurso dos alunos que não frequentaram a DCG e depois o discurso dos alunos que a frequentaram, para, então, compará-los.

As informaçóes contidas nas entrevistas geraram seis ideias centrais, três para os participantes da DCG e três para os que não participaram. A seguir, apresentam-se os DSCs referentes às percepçóes dos participantes sobre a influência do conceito de TS na construção de TA.

\subsection{Tema 1 - O que é Tecnologia Social}

\subsubsection{Ideia Central 1 - Tecnologia de baixo custo (não participantes da DCG)}

\begin{abstract}
Acredito que sejam meios como: equipamentos, métodos, técnicas que sejam desenvolvidos utilizando a questão do baixo custo, que sejam mais simples, de fácil acesso, que busquem resolver problemas de ordem social, desenvolvendo assim os recursos $d a$ própria comunidade, aliado com o conhecimento científico. Seria uma tecnologia de baixo custo, visando pessoas de baixo poder aquisitivo, mais carentes ou que morem em locais onde náo tenha muita matéria prima que possibilite fazer uma tecnologia mais moderna, é algo que você faz em prol da comunidade, por um bem maior da comunidade.
\end{abstract}

Durante as entrevistas, os alunos colocam que a TS consistiria em equipamentos, técnicas ou métodos desenvolvidos levando-se em conta o baixo custo e a simplicidade. Seriam tecnologias de fácil acesso que solucionam problemas de ordem social. Frisam, ainda, que seria uma tecnologia pensada para locais em que não se tenha disponibilidade de diferentes materiais. Observa-se, assim, que, para este grupo, a TS representa uma solução caritativa e não um direito.

Costa (2013) refuta essa ideia quando discute que a TS é uma importante tecnologia que se difere das demais justamente por buscar uma melhora na qualidade de vida e procurar soluções para determinadas demandas que se relacionem com a realidade local em que ela vai ser aplicada. É uma tecnologia desenvolvida e pensada junto com a população, uma produção/construção coletiva, que vai fazer com que os envolvidos no processo conheçam suas capacidades e ampliem seus conhecimentos, apropriando-se do processo e auxiliando na construção da TS.

Os alunos ressaltam, também, que as TS, em função do adjetivo social, consistem em equipamentos de baixo custo ou construídos para pessoas de baixa renda. Costa (2013) salienta a confusão que o termo social produz no discurso sobre esse tema quando discute que o vocábulo "social" não significa uma tecnologia pensada para as camadas mais pobres, mas sim uma lógica de tecnologia mais sustentável e solidária para todas as camadas da sociedade.

A partir das discussões do autor, observa-se que, no discurso dos alunos, não está presente o caráter 
participativo da TS, porque em nenhum momento foi salientado o envolvimento das pessoas na construção dessas tecnologias. Além disso, a questão do empoderamento, da melhoria na qualidade de vida e da transformação visando à inclusão social também não foi mencionada pelos alunos no discurso.

\subsubsection{Ideia Central 2 - Ações desenvolvidas em conjunto e construídas com base em uma demanda (participantes da DCG)}

Tecnologia Social é uma tecnologia mediadora que a base dela é articulação entre a comunidade, a demanda da comunidade e a pessoa ou instituição, por exemplo. Vejo Tecnologia Social como um espaço, um momento onde as pessoas construam juntas em favor de alguém ou de um grupo de pessoas, mas que todos da comunidade possam estar envolvidos na construção das tecnologias. São produtos e açôes desenvolvidas a partir de métodos ou técnicas em conjunto entre profissionais e a comunidade que visam promover soluçôes para determinados problemas sociais, desta forma ela vai proporcionar, consequentemente, melhorias importantes na vida dessas pessoas. São vários os tipos de tecnologias sociais que podemos construir a partir da demanda do sujeito e ela é criada com materiais mais baratos para poder ter uma economia no material e até reutilizar muitos produtos para que vire uma tecnologia de apoio. É uma tecnologia bem inovadora, que presa o desenvolvimento social.

Como se pode observar nesse discurso, os alunos constroem uma definição mais complexa sobre o conceito, ressaltando que a TS é uma intervenção importante, que se destaca pela busca da ampliação da qualidade de vida da população a partir de soluçóes que se relacionam muito com a realidade local em que se aplica. Entendem, ainda, que, geralmente, as demandas são identificadas pela própria população de acordo com suas necessidades, levando em consideração o conhecimento da população para essa construção, sem abordar, contudo, questóes importantes, como a autogestáo, a conscientização e a geração de novos saberes para que os envolvidos se apropriem desses novos conhecimentos para reaplicá-los, quando necessário. Dessa maneira, ainda não fazem uma definição completa sobre TS.

Preslei et al. (2012) discutem que as açôes de conscientização buscam a propagação da informação, sendo tal aspecto considerado um componente importante da TS, pois, a partir do diálogo e da troca de saberes, entre profissionais e comunidade, pode-se construir, de forma compartilhada, novos saberes.

O Instituto de Tecnologia Social (2010) complementa essa discussão, mencionando que a TS se une ao contexto e à realidade concreta dos sujeitos para transformá-la. É um situar-se no mundo das pessoas e em seu espaço, atentando para sua organização, de forma independente, autônoma e autogestionária. A TS é um instrumento pedagógico, por meio do qual todos aprendem durante a construção das soluçóes.

Comparando-se o posicionamento dos alunos que não cursaram a DCG ao dos alunos que cursaram, percebe-se que estes indicam conhecer a existência de uma preocupaçáo com a melhoria da qualidade de vida, considerando o conhecimento da população e a realidade do local. Assim, salientam a demanda do indivíduo ou da comunidade, e ampliam a definição quando mencionam que a TS é uma tecnologia de apoio.

Ainda segundo o instituto, a TS evidencia a estratégia de como os sujeitos do território se envolvem no enfrentamento de desafios. É uma fotografia da demanda efetiva de uma comunidade e de suas respostas às suas demandas (INSTITUTO..., 2010).

\subsection{Tema 2 - O que é Tecnologia Assistiva}

\subsubsection{Ideia Central 3 - Recursos, adaptações, equipamentos de auxílio para as pessoas/produto pronto (não participantes da DCG)}

\begin{abstract}
São recursos, equipamentos, adaptaçôes que buscam, possibilitam, facilitam, auxiliam as pessoas nas questöes do seu desempenho ocupacional. Pode ser um engrossador de caneta, de lápis, algum garfo adaptado, alguma tela, tecla de computador adaptado. Então a Tecnologia Assistiva seria aquele, aquela adaptação criada, desenvolvida visando à autonomia do indivíduo, facilitando o cotidiano do mesmo.
\end{abstract}

De acordo com esse discurso, os alunos relatam que a TA consiste em produtos pensados e criados que auxiliam as pessoas nas questóes do desempenho ocupacional. Seria uma adaptação desenvolvida para facilitar o cotidiano das pessoas visando à sua 
autonomia. A TA, neste caso, náo é compreendida como uma área do conhecimento e sim como um produto.

Segundo Berschi (2008), os exemplos citados nessas falas centram-se nas categorias de auxílio para a vida diária e a vida prática, e nos recursos de acessibilidade ao computador. A autora menciona, ainda, que os recursos de TA são organizados ou classificados de acordo com objetivos funcionais a que se destinam. Sáo 11 categorias: auxílios para a vida diária e vida prática; comunicação aumentativa e alternativa; recursos de acessibilidade ao computador; sistemas de controle de ambiente; projetos arquitetônicos para acessibilidade; órteses e próteses; adequaçáo postural; auxílios de mobilidade; auxílios para cegos ou para pessoas com visão subnormal; auxílios para pessoas com surdez ou com déficit auditivo, e adaptaçóes em veículos.

O fato de a TA ser considerada uma área do conhecimento é importantíssimo, pois se refere a vários recursos, como estratégias, práticas e serviços, não se restringindo a uma concepção de produto (BERSCH, 2014).

De acordo com Mello (1998), a TA também pode ser classificada como assistiva versus reabilitadora ou educacional, simples versus sofisticada, concreta versus teórica, equipamentos versus instrumentos, geral versus específica, e comercializada versus individualizada. No discurso apresentado pelos alunos, temos apenas exemplos de tecnologias simples e concretas.

Nota-se que os alunos não tratam de questóes importantes a respeito do conceito de TA, como a sua interdisciplinaridade, essencial para trabalhar a qualidade de vida, a inclusão social, a funcionalidade e a participação de pessoas com deficiência, incapacidade ou mobilidade reduzida; eles fixam-se apenas em uma parte do conceito de TA: o produto.

Para Garcia, Oliveira e Bergamashi (2015), a TA vem adquirindo um grande espaço em nosso cotidiano, pois promove melhorias e gera soluçóes no que diz respeito às limitaçôes das pessoas com deficiência, proporcionando maior qualidade de vida em um paradigma inclusivo.

Rossit et al. (2012) discutem que a interdisciplinaridade favorece o redimensionamento das relaçóes entre diferentes conteúdos, implicando, também, troca de experiências e novas interaçóes entre a equipe e assumindo, assim, um papel de articulação dos saberes. Trata-se de um conhecimento que se desdobra em diversos horizontes e permite mudanças.

\subsubsection{Ideia Central 4 - Tecnologia que busca auxiliar as pessoas, levando em conta o contexto (participantes da DCG)}

\begin{abstract}
A Tecnologia Assistiva é uma tecnologia que é construida para um sujeito buscando diminuir alguma dificuldade que ele tenha em relação ao contexto em que ele está. São criadas a partir de conhecimentos especificos e compreendem produtos ou recursos que objetivam promover uma funcionalidade e consequentemente independência $e$ autonomia para as pessoas que por quaisquer motivos tenham suas capacidades reduzidas. Podem ser adaptaçóes para alimentação, para vestuário, para o autocuidado, podem ser rampas, barras, mudanças na estrutura do local que também ajuda a essa pessoa a se locomover a ser mais independente possivel, visando sempre à independência.
\end{abstract}

Como se pode observar, para esses alunos, a TA é uma tecnologia construída para alguém com o objetivo de ampliar sua capacidade, levando-se em conta o contexto. Consideram que o intento da TA seja a ampliação da funcionalidade, independência e autonomia do sujeito, revelando um conceito sobre um produto e náo sobre uma área, embora mencionem a intervenção no ambiente.

As categorias elencadas nos exemplos transcritos são auxílios para a vida diária e a vida prática, e projetos arquitetônicos para acessibilidade. Nesse sentido, percebe-se a incorporaçáo do ambiente, o que mostra que os alunos deixam de pensar a TA apenas como um objeto que auxilia em questóes dentro de casa ou de uma sala de aula, e adentram no conceito do Desenho Universal, um conceito que visa à construção de uma sociedade mais inclusiva. Fica claro que os objetivos e a complexidade da TA se mostram ampliados em comparação às noções dos alunos não participantes da DCG.

De acordo com García e Galvão Filho (2012), considerar o conceito do Desenho Universal é importante para a discussáo sobre TA, porque traz a ideia de que todos os ambientes na sociedade devem ser projetados com vistas à participaçáo, à utilizaçáo e ao acesso de todas as pessoas. Portanto, essa concepção vai além de projetos específicos, adaptaçóes e espaços segregados, que respondem apenas a determinadas necessidades.

Percebe-se que, em relação ao discurso anterior, ocorre uma discussão mais ampla sobre a complexidade das ações em TA, as quais não se centram apenas em objetos. Os alunos abordam novas questóes, tais como a funcionalidade e a independência, consideradas 
finalidades da TA. Além disto, observam, também, o contexto da pessoa, algo que é essencial, pois compreendem as questóes que envolvem o sujeito e o seu ambiente.

Cruz (2012) afirma que utilizar várias tecnologias contempla atualmente um modelo de política de saúde cujo foco não está somente nas funçóes corporais, mas também nas questốes do desempenho nas atividades, da participação e dos fatores de contexto pessoal e ambiental, para que haja condiçôes de saúde plena, contemplando o discurso transcrito.

Apesar de o conceito apresentado pelos alunos que frequentaram a DCG abordar mais questóes do que o anterior, ainda não se tem uma definição completa de TA. Novamente, a característica interdisciplinar não é apresentada no discurso, assim como a inclusão social.

Observa-se que, embora a discussão sobre o contexto seja realizada, ainda náo há o debate sobre a participação no processo de construção de TA.

\subsection{Tema 3 - Prescrição de TA através dos princípios da TS}

\subsubsection{Ideia Central 5 - Prescrições utilizando materiais de baixo custo encontrados na comunidade (não participantes da DCG)}

Uma das formas de construir as tecnologias assistivas seria utilizando os recursos disponiveis na comunidade em que o usuário está inserido, aliando o saber cientifico com o conhecimento do serviço, da própria comunidade, visando à questão da realidade do sujeito para construir essas tecnologias. Vocêpode criar algum utensilio, adaptar algum utensilio com um material de baixo custo dentro da realidade do sujeito que está precisando. Seriam projetos partindo do conhecimento do contexto, primeiramente em que o individuo está inserido, conhecendo o território dele, a área, a comunidade, a realidade dele e então, a partir disso, o terapeuta conseguir subsidios ali mesmo para construir essa tecnologia.

Quando se trata de prescrição de TA, Mello (1998) traz alguns fatores que são considerados importantes para garantir o uso eficiente, como olhar o sujeito como um todo e náo somente tendo em vista a função perdida; considerar o que o indivíduo pensa e sente sobre o dispositivo; pensar no impacto social que este dispositivo poderá causar, e fazer com que o dispositivo se acomode ao estilo cognitivo/físico/mental da pessoa. Além dessas questóes, é necessário um período de adaptação, treinamento e acompanhamento.

A TA, quando desenvolvida a partir da TS, tem uma finalidade explícita, a de dar maior autonomia, proporcionar maior participação, possibilidades e inclusão social às pessoas com deficiência (GARCIA, 2014).

Nesse discurso, os alunos mencionam que, para construir TA a partir dos princípios da TS, dever-se-iam utilizar recursos disponíveis na própria comunidade, considerando sua realidade. Mencionam que terapeutas ocupacionais podem construir essas tecnologias a partir do local e também de materiais encontrados na própria comunidade. Novamente, o fato de que tais tecnologias ou projetos seriam de baixo custo encontra-se presente no discurso.

Além disso, de acordo com as falas observadas, o terapeuta ocupacional considera o contexto, mas conhece a comunidade com o objetivo de conseguir material para construção do produto (matéria-prima) e, depois, encaminhá-lo para o indivíduo.

Isso não significa, entretanto, que toda a TS precisa, necessariamente, ter baixo custo ou que, para ser considerado um projeto de TS, precisa ter baixo custo. $\mathrm{O}$ baixo custo pode facilitar sua construção e torná-la mais acessível (BRASIL, 2007).

\subsubsection{Ideia Central 6 - Projetos construídos com o sujeito de forma interdisciplinar (participantes da DCG)}

Tanto a Tecnologia Social como a Assistiva, penso que isso seja mais forte na Social, deve-se trabalhar com o sujeito e náo para o sujeito, porque a maioria das coisas que construimos é pensada da seguinte forma "eu vou construir para ti e não contigo" $e$ isso é primordial para o sucesso do dispositivo. Então construir uma Tecnologia Assistiva que vá beneficiar aquele individuo no viés da Tecnologia Social é muito importante, justamente por toda a base de diálogo que a Tecnologia Social propóe, desta forma você irá construir algo próximo daquela comunidade ou daquela pessoa, algo construido em conjunto torna-se muito útil para a pessoa e diminuía iatrogenia. É muito tranquilo você conversar com a pessoa, ver qual é a realidade, qual é a possibilidade de construir esta tecnologia na comunidade para empoderar a comunidade, empoderar aquele sujeito. Esses projetos seriam interdisciplinares, várias pessoas envolvidas como a Terapia Ocupacional, e Desenho Industrial, a Engenharia Civil, todos esses cursos juntos pensando 
em projetos que auxiliem o sujeito e de forma mais barata. Todos trabalhando para que se consiga ver a situação de uma determinada pessoa e, a partir do olhar de todas essas pessoas confeccionar o que ela precisa, o que estava necessitando naquele momento.

Nesse discurso, é possível perceber que a prescrição de projetos de TA, a partir dos princípios da TS, deve ser feita de modo coletivo, com a participação do sujeito nas diferentes etapas de construção da TA, visando à iatrogenia e tornando a tecnologia mais útil para a pessoa. Reforçam que seriam projetos interdisciplinares, em que todos pensariam e trabalhariam juntos para empoderar a comunidade e o sujeito. Seriam projetos construídos a partir do olhar de todas as pessoas.

Bersch (2014) complementa essa discussão sobre construção coletiva quando traz que, nessas construçôes, sujeitos e profissionais precisam formar uma equipe. $\mathrm{O}$ sujeito conhece sua realidade, a realidade/contexto em que vive e sabe quais os limites e as possibilidades desse contexto, e conhece também o problema que deseja superar com o uso da tecnologia. A partir dessas informaçóes e demandas, os profissionais buscam soluçôes para os problemas trazidos. Com esta interação, há troca de saberes e resultados mais positivos.

Cruz (2012) reforça esse discurso quando discute que o empoderamento também é uma forma de as pessoas com deficiência irem à busca dos seus direitos, fazendo valer o que é constituído e público pelas leis vigentes. Alerta, ainda, para o fato de que essa falta de conhecimento repercute no desuso da tecnologia.

Ainda segundo Cruz (2012), outras questôes que levam ao abandono da tecnologia são, por exemplos, o nâo reconhecimento das pessoas quanto aos benefícios a que têm direito; o uso incorreto dessas tecnologias; as questōes estéticas; as barreiras arquitetônicas, e a não consideração do indivíduo durante o processo de escolha do equipamento a ser utilizado.

Novamente, amplia-se a complexidade na construção do discurso sobre a construção desses projetos. Os alunos mencionam a construçáo coletiva e o empoderamento dos envolvidos, o que é essencial, pois este é o diferencial da TS. Além disso, citam a importância da interdisciplinaridade, o que é condição essencial quando se pensa em TA e TS, pois a TS usa o conhecimento dos vários atores envolvidos para criar novos saberes. A participação também é lembrada - uma forma de ampliar a adesão ao uso.

Tanto a TA como a TS devem ser entendidas como recursos pensados para o sujeito e náo como recursos de um profissional ou de uma área específica. Nos estudos de Scherer, Pires e Jean (2013), conclui-se que a interdisciplinaridade necessita do uso integrado do conhecimento das práticas, invadindo fronteiras disciplinares. O autor explicita, ainda, que a interdisciplinaridade é construída a partir de necessidades e capacidades determinadas pelos sujeitos e pelo meio, produzindo o cuidado em saúde.

Costa (2013) entende que o conhecimento local e a participação da população são os principais elementos constituintes da TS. Com o conhecimento local, surgem novas abordagens para resolver os problemas e a participação popular garante a efetividade da tecnologia, pois a vivência com a situaçáo-problema dos envolvidos, aliando seus saberes, confere ao sujeito uma participação ativa dentro da construção.

Percebe-se que, em ambos os discursos sobre a construçáo de TA, quando se acrescentou a TS, os conceitos tornaram-se mais abrangentes, pois foram trazidas à tona questóes, como contexto e participação, o que, nos discursos anteriores, não ocorreu.

Assim, é lícito afirmar que incluir os princípios da TS nas discussōes de TA (BRASIL, 2009) pode incentivar o desenvolvimento de projetos que contemplem em sua metodologia a apropriação, a participação, o empoderamento e a autogestão dos envolvidos, gerando, consequentemente, inclusão social.

\section{Conclusão}

A utilização da metodologia qualitativa para a apreensão das percepçóes dos alunos sobre a TS e a TA, visualizadas por meio do DSC, permitiu conhecer aspectos relevantes sobre esses projetos.

Trabalhar em concomitância com a TS pode ser interessante em função das questóes de participação, transferência de saber, interdisciplinaridade e ampliação do acesso que são envolvidas, pois, quando se acrescenta a participaçáo no processo de desenvolvimento dessas tecnologias, a possibilidade de abandono é diminuída. Dessa forma, é possível formar terapeutas aptos a resolver problemas e a desenvolver metodologias mais resolutivas e reaplicáveis.

Diante disso, observa-se que, de forma geral, pelos dois grupos, não foram discutidas questôes importantes que envolvem o conceito de TS e TA, como a autogestáo, a reaplicação e o fato de que são áreas do conhecimento. Entende-se que seja necessário pensar em estratégias de ensino que incentivem a discussão dessas temáticas, fornecendo um estímulo para que os alunos compreendam a complexidade da TA e não a definam apenas como um produto. 
Este estudo se limita ao curso de Terapia Ocupacional da Universidade Federal de Santa Maria, porém a realizaçáo de outros estudos em outros cursos de Terapia Ocupacional de diferentes universidades seria interessante, para analisar como outras universidades têm trabalhado esta relação entre a TA e a TS.

\section{Referências}

BERSCH, R. Tecnologia assistiva ou tecnologia de reabilitaçáo? In: SIMPÓSIO INTERNACIONAL DE TECNOLOGIA ASSISTIVA, 1., 2014, Campinas. Anais... Campinas: CNRTA-CTI, 2014. p. 45-50.

BERSCHI, R. Introdução à tecnologia assistiva. Porto Alegre: Centro Especializado em Desenvolvimento Infantil, 2008.

BRASIL. Ministério da Ciência, Tecnologia e Inovação. Diretrizes da Tecnologia Social. Brasília, 2012. Disponível em: <http://www.mct.gov.br/index.php/content/ view/78536/Diretrizes.html>. Acesso em: 15 jun. 2015.

BRASIL. Secretaria Especial dos Direitos Humanos da Presidência da República. Comitê de Ajudas Técnicas CAT. Ata da Reunião VII realizada nos dias 13 e 14 de dezembro de 2007. Brasília, 2007.

BRASIL. Subsecretaria Nacional de Promoção dos Direitos da Pessoa com Deficiência. Comitê de Ajudas Técnicas - CAT. Tecnologia assistiva. Brasília, 2009.

COSTA, A. B. (Org.). Tecnologia social e politicas públicas. São Paulo: Instituto Pólis; Brasília: Fundação Banco do Brasil, 2013.

CRUZ, D. M. C. Papéis ocupacionais e pessoas com deficiências fisicas: independência, tecnologia assistiva e poder aquisitivo. 2012. 229 f. Tese (Doutorado em Educaçáo Especial) - Universidade Federal de São Carlos, São Carlos, 2012.

FERNANDES, R. M. C.; MACIEL, A. L. S. Caminhos das Tecnologias Sociais: reflexôes iniciais. In: FERNANDES, R. M. C.; MACIEL, A. L. S. Tecnologias sociais: experiências e contribuiçôes para o desenvolvimento social e sustentável. Porto Alegre: Fundação Irmão José Otáo, 2010. p. 40-43.

GALVÃO FILHO, T. A. A Tecnologia Assistiva: de que se trata? In: MACHADO, G. J. C.; SOBRAL, M. N. (Org.). Conexóes: educação, comunicação, inclusão e interculturalidade. Porto Alegre: Redes Editora, 2009. p. 207-235.

GARCIA, J. C. D. Deficiência e Tecnologia Assistiva: Conceitos e Implicações para as Políticas Públicas. In: SIMPÓSIO INTERNACIONAL DE TECNOLOGIA ASSISTIVA, 1., 2014, Campinas. Anais... Campinas: CNRTA-CTI, 2014.

GARCÍA, J. C. D.; GALVÃO FILHO, T. A. Pesquisa nacional de tecnologia assistiva. Sáo Paulo: ITS Brasil/ MCTI-Secis, 2012.
GARCIA, L. P.; OLIVEIRA, T. M.; BERGAMASHI, M. P. O futuro é para todos: um comparativo entre a realidade da tecnologia assistiva do Brasil e as açóes do governo na quebra do paradigma inclusivo. UNISANTA Humanitas, Santos, v. 4, n. 1, p. 10-17, 2015.

INSTITUTO DE TECNOLOGIA SOCIAL - ITS. Caderno de debate. Tecnologia Social no Brasil. São Paulo: ITS, 2004.

INSTITUTO DE TECNOLOGIA SOCIAL - ITS. Conhecimento e cidadania 1. Tecnologia Social. Sáo Paulo: ITS, 2007.

INSTITUTO DE TECNOLOGIA SOCIAL - ITS Tecnologia Social e Desenvolvimento Sustentável: Contribuiçôes da RTS para a formulação de uma Política de Estado de Ciência, Tecnologia e Inovação. Brasília: Secretaria Executiva da Rede de Tecnologia Social, 2010.

LEFÈVRE, F.; LEFÈVRE, A. M. C. O discurso do sujeito coletivo: um novo enfoque em pesquisa qualitativa (desdobramentos). Caxias do Sul: Educs, 2005.

LOPES, R. E. et al. Oficinas de atividades com jovens da escola pública: tecnologias sociais entre educação e terapia ocupacional. Interface - Comunicação, Saúde, Educação, Botucatu, v. 15, n. 36, p. 277-288, 2011.

MARINS, S. C.; EMMEL, M. L. G. Formação do terapeuta ocupacional: acessibilidade e tecnologias. Cadernos de Terapia Ocupacional da UFSCar, São Carlos, v. 19, n. 1, p. 37-52, 2011.

MELLO, M. A. F. Tecnologia assisitiva. In: AMATUZZI, M. M.; GREVE, J. M. D. A. (Org.). Medicina de reabilitação aplicada à ortopedia e traumatologia. São Paulo: Roca, 1998. p. 270-278.

PELOSI, M. B. O papel do terapeuta ocupacional na Tecnologia Assistiva. Cadernos de Terapia Ocupacional da UFSCar, São Carlos, v. 13, n. 1, p. 39-45, 2005.

PELOSI, M. B. Os terapeutas ocupacionais das unidades de saúde do município do Rio de Janeiro e suas açóes na área de Tecnologia Assistiva. Revista Teias, Rio de Janeiro, v. 11, n. 23, p. 149-162, 2010.

PRESLEI, A. K. A. et al. Tecnologia social e prática educativa sobre osteoporose para um grupo de agentes promotores de saúde segundo a abordagem dialógica. Saúde \& Transformação Social, Florianópolis, v. 3, n. 4, p. 25-30, 2012.

ROSSIT, R. A. S. et al. Aprendizagem e interdisciplinaridade formação na saúde. São Paulo: Unifesp, 2012.

SCHERER, M. D. A.; PIRES, D. E. P.; JEAN, R. A construção da interdisciplinaridade no trabalho da Equipe de Saúde da Família. Revista Ciência e Saúde Coletiva, Brasília, v. 18, n. 11, p. 3203-3212, 2013.

SILVA, A. C.; ALENCAR, M. H. B. C. Tecnologia social visando à promoçáo de saúde em uma comunidade rural de São Luís, MA. Saúde \& Transformação Social, Florianópolis, v. 5, n. 1, p. 66-72, 2014.

VARELA, R. C. B. Crianças com deficiência: compreendendo seu cotidiano e a importância do uso de recursos 
tecnológicos na atenção em Terapia Ocupacional. 2010. 212 f. Dissertação (Mestrado em Medicina) - Universidade de São Paulo, São Paulo, 2010.
WORLD FEDERATION OF OCCUPATIONAL THERAPY - WFOT. Definiçōes de Terapia Ocupacional. São Paulo: CETO, 2001.

\section{Contribuição dos Autores}

Letícia Reichert foi responsável pelas entrevistas, pelo levantamento de dados e pela concepçâo do texto. Taísa Gomes Ferreira foi responsável pela orientação da pesquisa e pela revisão do artigo. Ambas autoras aprovaram a versão final do texto. 